\title{
Do roots mind the gap?
}

\author{
A. Carminati • D. Vetterlein • N. Koebernick • \\ S. Blaser • U. Weller $\cdot$ H.-J. Vogel
}

Received: 20 July 2012 / Accepted: 11 October 2012 / Published online: 31 October 2012

(C) The Author(s) 2012. This article is published with open access at Springerlink.com

\begin{abstract}
Aims Roots need to be in good contact with the soil to take up water and nutrients. However, when the soil dries and roots shrink, air-filled gaps form at the rootsoil interface. Do gaps actually limit the root water uptake, or do they form after water flow in soil is already limiting?

Methods Four white lupins were grown in cylinders of $20 \mathrm{~cm}$ height and $8 \mathrm{~cm}$ diameter. The dynamics of root and soil structure were recorded using X-ray CT at regular intervals during one drying/wetting cycle. Tensiometers were inserted at 5 and $18 \mathrm{~cm}$ depth to measure soil matric potential. Transpiration rate was monitored by continuously weighing the columns and gas exchange measurements.
\end{abstract}

Responsible Editor: Peter J. Gregory.

Electronic supplementary material The online version of this article (doi:10.1007/s11104-012-1496-9) contains supplementary material, which is available to authorized users.

A. Carminati $(\triangle)$

Division of Soil Hydrology,

Georg-August Universität Göttingen,

Büsgenweg 2,

37077 Göttingen, Germany

e-mail: acarmin@gwdg.de

D. Vetterlein $\cdot$ N. Koebernick $\cdot$ S. Blaser $\cdot$ U. Weller $\cdot$

H.-J. Vogel

Soil Physics Department,

Helmholtz Centre for Environmental Research - UFZ,

Halle, Germany
Results Transpiration started to decrease at soil matric potential $\psi$ between $-5 \mathrm{kPa}$ and $-10 \mathrm{kPa}$. Air-filled gaps appeared along tap roots between $\psi=-10 \mathrm{kPa}$ and $\psi=-20 \mathrm{kPa}$. As $\psi$ decreased below $-40 \mathrm{kPa}$, roots further shrank and gaps expanded to 0.1 to $0.35 \mathrm{~mm}$. Gaps around lateral roots were smaller, but a higher resolution is required to estimate their size.

Conclusions Gaps formed after the transpiration rate decreased. We conclude that gaps are not the cause but a consequence of reduced water availability for lupins.

Keywords Root water uptake $\cdot$ Root-soil contact . Transpiration rate $\cdot$ Root shrinkage $\cdot \mathrm{X}$-ray CT

\section{Introduction}

Continuity of water flow between soil and roots is essential to sustain the plant transpiration demand. In a recent review, Draye et al. (2010) discussed the relative importance of soil and root hydraulic properties for water availability to plants. Referring to the classic paper by Passioura (1980), they stated that when the soil is wet it has little influence on water availability, while when the soil is dry it controls water uptake. When the soil is neither too wet nor too dry, water uptake depends on both soil and plant properties. In this range of soil conditions, the root-soil interface may play an important role.

Distinct and unique properties of the root-soil interface have often been invoked in the literature. We 
refer to several recent reviews on the specific physical, chemical, biological properties of the rhizosphere (Gregory 2006; Hinsinger et al. 2009); to measurements of water content (Young 1995), structure (Whalley et al. 2005), wettability (Read et al. 2003), and mechanical stability (Czarnes et al. 2000) of the rhizosphere compared to bulk soil; to in-situ infiltration in the rhizosphere (Hallet et al. 2003); and to recent observations of unexpected water dynamics in the rhizosphere (Carminati et al. 2010). These studies show several controversies, for example in whether the rhizosphere has increased or decreased water content and conductivity compared to the bulk soil. One conclusion that can be drawn is that the rhizosphere has dynamic and complex characteristics that are not understood sufficiently at present.

In this study we focus on one specific aspect of root-soil properties, the formation of gaps at the rootsoil interface. Root shrinkage and consequent loss of contact with the soil were observed by Huck et al. (1970) in experiments with roots growing in soil along a glass plate. Such experiments are prone to artifacts, in particular regarding soil structure. An alternative approach is based on resin-impregnation and thinsectioning (Veen et al. 1992; North and Nobel 1997). However, this method does not allow the observation of the temporal evolution of the gaps. Today, recent advances in X-ray computer tomography allow visualization of roots in soil in samples large enough to accommodate three-dimensional root growth at the spatial resolution required to observe gaps at the root-soil interface. By using local tomography and zooming inside the sample, Carminati et al. (2009) were able to monitor the formation of gaps at the interface between roots of a lupin in a sandy soil with a spatial resolution of $0.1 \mathrm{~mm}$. Higher resolution (pixel size of $4.4 \mu \mathrm{m}$ ) was achieved by Aravena et al. (2011). They studied soil compaction around roots by means of synchrotron X-ray microtomography.

While the presence of gaps at some root locations is well documented, the effect of gaps on water uptake is not well understood. Do gaps limit root water uptake? Few studies have simultaneously measured gap formation, transpiration rate, and soil and plant water status. Important work has been performed by Nobel and co-workers (Nobel and Cui 1992; North and Nobel 1997). Nobel and Cui (1992) measured the hydraulic conductance of soil and roots of a desert succulent and they compared them to the conductance of an air-filled gap, assuming water flow only via the vapor phase. In Fig. 5 they showed that root conductivity was limiting when soil was wet, soil conductivity was limiting when soil was dry, and, in an intermediate soil moisture regime, the gap was the limiting factor for the water flow to roots, which is in agreement with the more general statement by Passioura (1980) and Draye et al. (2010) reported above.

The reason why there are so few studies of gap effects on water flow is the difficulty of measuring simultaneously and at the required spatial resolution gap dynamics, soil matric potential, soil conductivity and xylem water potential. Nobel and Cui (1992) solved this difficulty by separately measuring each component of the soil-plant continuum and then piecing them together as a flow in series. However, in such a way, rhizosphere processes and gradients in water potential towards the root, which are expected to become increasingly important as soil dries, cannot be included. Additionally, in Nobel and Cui (1992) root shrinking and swelling were measured for excised roots and all root parts were assumed to shrink uniformly.

The present study aimed to extend the results of Carminati et al. (2009) in which soil water status was monitored simply by weighing the columns once a day. Here, we intend to relate gap dynamics with transpiration rate and soil water potential more accurately. To this end, we combined the information from tomography with measurements of transpiration rate, water content and soil water potential during one drying and wetting cycle.

The specific questions posed are: at what soil water potentials do gaps form? Where do they form along the root systems - i.e. tap root versus laterals? And most importantly, do gaps limit transpiration rate and the plant water balance?

\section{Materials and methods}

Four cylinders of $8-\mathrm{cm}$ diameter and $20-\mathrm{cm}$ height were filled with sandy soil collected from the field site "Hühnerwasser" (Germany). The soil consisted of $92 \%$ sand, $5 \%$ silt and $3 \%$ clay. The soil was sieved to $2 \mathrm{~mm}$ and then poured into the cylinders through two sieves placed at a $10-\mathrm{cm}$ distance from each other. This filling procedure was chosen to obtain a homogeneous packing (Glass et al. 1989). The soil bulk 
density was $1.45 \pm 0.045 \mathrm{~g} \mathrm{~cm}^{-3}$. The soil hydraulic properties were reported by Carminati et al. (2010). The water retention curve of this soil is plotted as supplementary information in the online version (Figure S2). Seeds of Lupinus albus L. (Feodora) were surface sterilized for $10 \mathrm{~min}$ in $10 \% \mathrm{H}_{2} \mathrm{O}_{2}$ and soaked for $1 \mathrm{~h}$ in saturated $\mathrm{CaSO}_{4}$ solution. One seed per column was placed in the soil at $1 \mathrm{~cm}$ depth. The soil surface was covered with a layer of coarse quartz gravel $(2-5 \mathrm{~mm})$ to reduce evaporation from the surface. Liquid fertilizer (7-3-6 Terrasan $\mathrm{GmbH}$, containing $7 \% \mathrm{~N}, 1.3 \% \mathrm{P}, 5 \% \mathrm{~K}$ ) was diluted $1: 100$ and $100 \mathrm{ml}$ of diluted solution per column was applied as the initial irrigation water. Columns were watered by capillary rise from the bottom. At the bottom of the columns a water table (soil matric potential $\psi=0 \mathrm{kPa}$ ) was maintained with deionized water until 10 days after planting. Then water supply was discontinued and plants were only irrigated again when they showed severe wilting symptoms. Plants were grown under controlled conditions $\left(23{ }^{\circ} \mathrm{C}\right.$ day $/ 23{ }^{\circ} \mathrm{C}$ night; $65 \%$ relative humidity; $14 \mathrm{~h}$ photoperiod with $350 \mu \mathrm{molm}^{-2} \mathrm{~s}^{-1}$ ) in a climate chamber. Microtensiometers as described by Vetterlein et al. (1993) were inserted at depths of $5 \mathrm{~cm}$ and $18 \mathrm{~cm}$. Throughout the experiment each column was placed on a balance and the weight was continuously recorded (10 min interval). From these data whole plant transpiration was calculated.

The four samples, named Lupin I-IV, were scanned using a X-ray micro-CT scanner (X-tex HMX 225). Our CT device was a cabinet model where the columns could be placed vertically during scanning. The source was a $5 \mu \mathrm{m}$ focal spot source. X-ray imaging was performed at two levels of spatial resolution and field of view. First we recorded the entire sample with a large field of view of $16.4 \mathrm{~cm} \times 16.4 \mathrm{~cm}$, voxel side length of $0.32 \mathrm{~mm}$, X-ray energy of $170 \mathrm{kV}$, current of $180 \mu \mathrm{A}$ and exposure time of $400 \mathrm{~ms}$. Then specific locations of the sample were imaged at higher resolution. We carried out local tomography of the upper part (2-7 cm depth) and lower part (12-17 cm depth) of the cylinder with a field of view of $5 \mathrm{~cm} \times 5 \mathrm{~cm}$ and voxel side length of $0.1 \mathrm{~mm}$. In local tomography, the field of view is smaller than the sample size and the reconstruction is focused on a subsample, resulting in a higher spatial resolution. This is possible as long as the region outside the field of view has no macroscopic structure. For the local tomography we decreased the energy to $135 \mathrm{kV}$, to improve contrast within the image. Consequently, we increased the current to $1,600 \mu \mathrm{A}$ and the exposure time to $360 \mathrm{~ms}$. The used CT set-up was a compromise between spatial resolution and field of view, that should be large enough to image a sufficient portion of tap root and laterals. We considered that a spatial resolution of $0.1 \mathrm{~mm}$ was sufficient to visualize the gap around a tap root with a diameter of approximately $2-3 \mathrm{~mm}$. However, a better resolution would be preferable for a detailed analysis of the gaps around lateral roots with diameter smaller than $0.5 \mathrm{~mm}$.

The samples were scanned by CT during the drying cycle and after irrigation. One complete scanning procedure took approximately $1 \mathrm{~h}$. During this period the plants were not illuminated.

Development of the total leaf area of plants was derived from daily counts of leaflets per plant and determination of leaf area of individual leaflets at harvest (average leaflet area of lupin was $2.07 \mathrm{~cm}^{2}$ ).

Tomography reconstruction and image processing were described by Carminati et al. (2009). Based on the large field of view, identification of roots was done following a segmentation protocol: first we applied a diffusion filter based on total variation (Rudin et al. 1992). Then a pseudomedian filter was applied to separate the structures (roots and gaps) from the soil matrix background. The difference between the filtered image and the original was then used to identify the roots via a region growing algorithm. The images were processed using QtQuantIm (www.quantim.ufz.de) (Vogel et al. 2010). For the quantitative analysis of gaps between soil and roots, we classified the voxels belonging to soil, gaps and roots. Segmentation of the local tomograms was performed after application of a median filter that smoothed the picture but preserved the borders between structures. Additionally, tap and lateral roots were distinguished based on their different radii by means of morphological opening and closing operations. Overlapping of different scans was done to have a visual and direct comparison of the samples at different time steps. The tomograms have been superimposed by visually matching several defined pairs of points and inversely calculating a least square fit for the transformation matrix. This procedure was performed with QtQuantim. All technical aspects of the image analysis were reported in Carminati et al. (2009). 


\section{Results}

Figure 1 (top) shows the soil matric potential at $5 \mathrm{~cm}$ depth of the four plants examined (Lupin I-IV) during the drying cycle. As a convention throughout this manuscript, we call day 0 the beginning of the drying experiment. During the first days, when the samples were relatively wet, the decrease in soil matric potential was slow. After a few days, the soil matric potential $\psi$ started to decrease more rapidly. This is simply explained by the non-linear relation between water content and $\psi$ (Figure S2). As $\psi$ became lower than $-30 \mathrm{kPa}$, it started to decrease more slowly (Lupin IIIV). This was caused by the reduced transpiration rate (Fig. 1, bottom). Variations among the samples were explained by a different growth rate of the plants. However, Fig. 1 (bottom) shows that when the transpiration rate started to decrease $\psi$ was between -5 and $-10 \mathrm{kPa}$ for all samples. In this sense the relation between $\psi$ and relative transpiration rate was similar for all samples. We will come back to this point later. The relative transpiration rates plotted in Fig. 1 (bottom) were calculated as the actual transpiration rate divided by the transpiration rate of the sample before the drying cycle. The decrease in transpiration at such a high matric potential ( $\psi$ was less negative than $-10 \mathrm{kPa}$ ) was explained by the low water holding capacity of the sandy soil. At $\psi=-10 \mathrm{kPa}$ the volumetric water content was approximately $7 \%$ and the soil hydraulic conductivity could be already limiting (Figure S2). Such an "early" decrease in transpiration for plants grown in a coarse soil was already reported by Carbon (1973). Carbon (1973) observed that at the pick of transpiration plants experienced a water stress although the soil was relatively wet (matric potential between 0 and $-100 \mathrm{kPa}$ ). Carbon (1973) calculated that root water uptake could not match the transpiration demand at $\psi<-5 \mathrm{kPa}$. Such a result is in
Fig. 1 Top: Soil matric potential at $5 \mathrm{~cm}$ depth during the drying cycle. Day 0 is the beginning of the drying period. Bottom: relative transpiration rate during the drying cycle. The relative transpiration rate was calculated as the ratio between the actual transpiration rate divided by the transpiration rate before starting the drying cycle
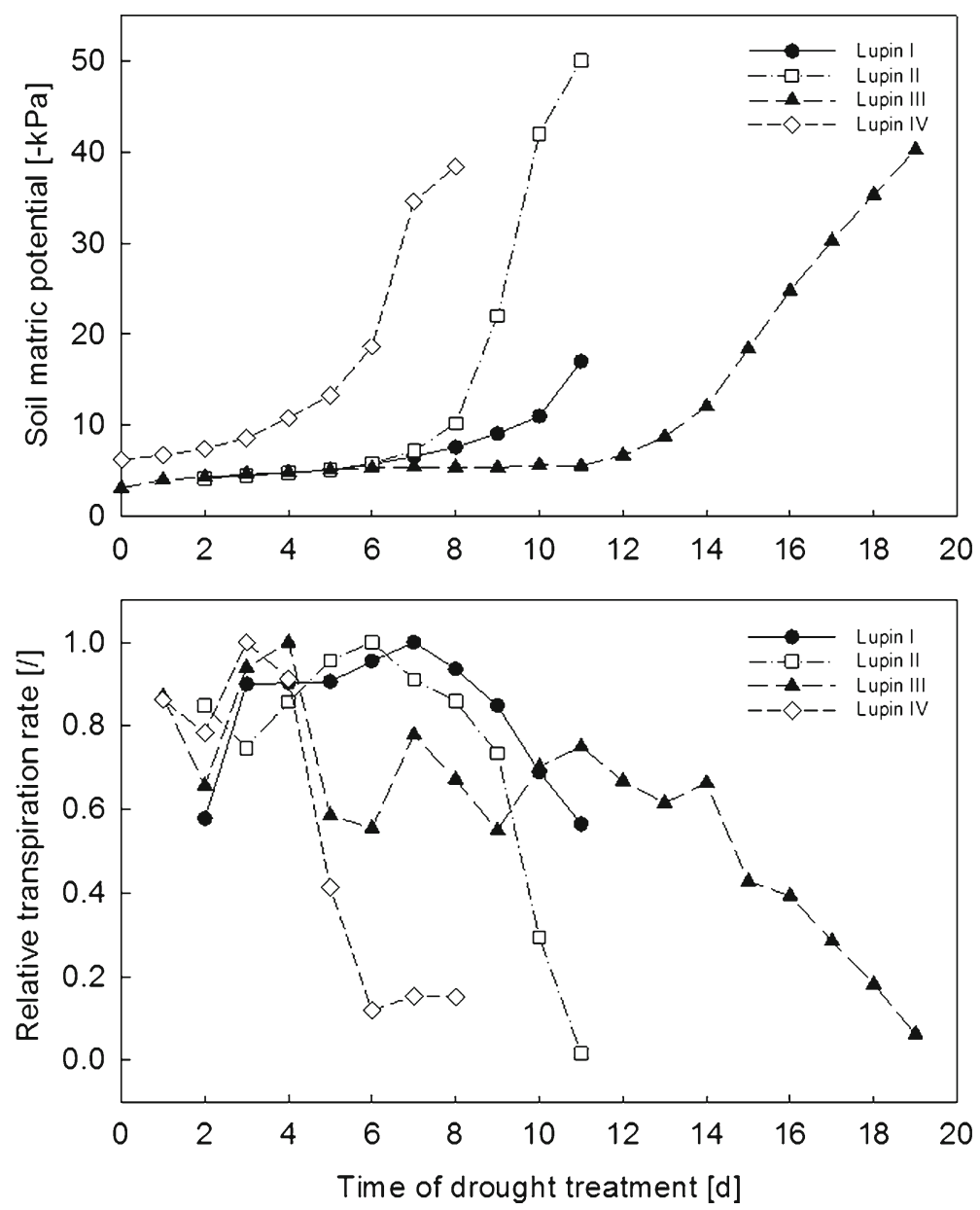
agreement with our measurements of transpiration rate versus water potential.

The root architecture of Lupin II at 9 days after the start of the drying period is visualized in Fig. 2. The tomography shows that the lupin had a tap root growing vertically and laterals growing radially towards the container walls and then continuing along the walls. Note that the field of view $(16.4 \times 16.4 \mathrm{~cm})$ did not fully cover the sample and the deepest few centimetres of the roots are not visible in the image. The other samples had a similar root architecture.

Vertical sections of the local tomography of the upper and lower parts of Lupin II on day 9, 10, 11, and 14 are shown in Fig. 3. The tomograms were aligned using the software QtQuantIm. In Fig. 3 the

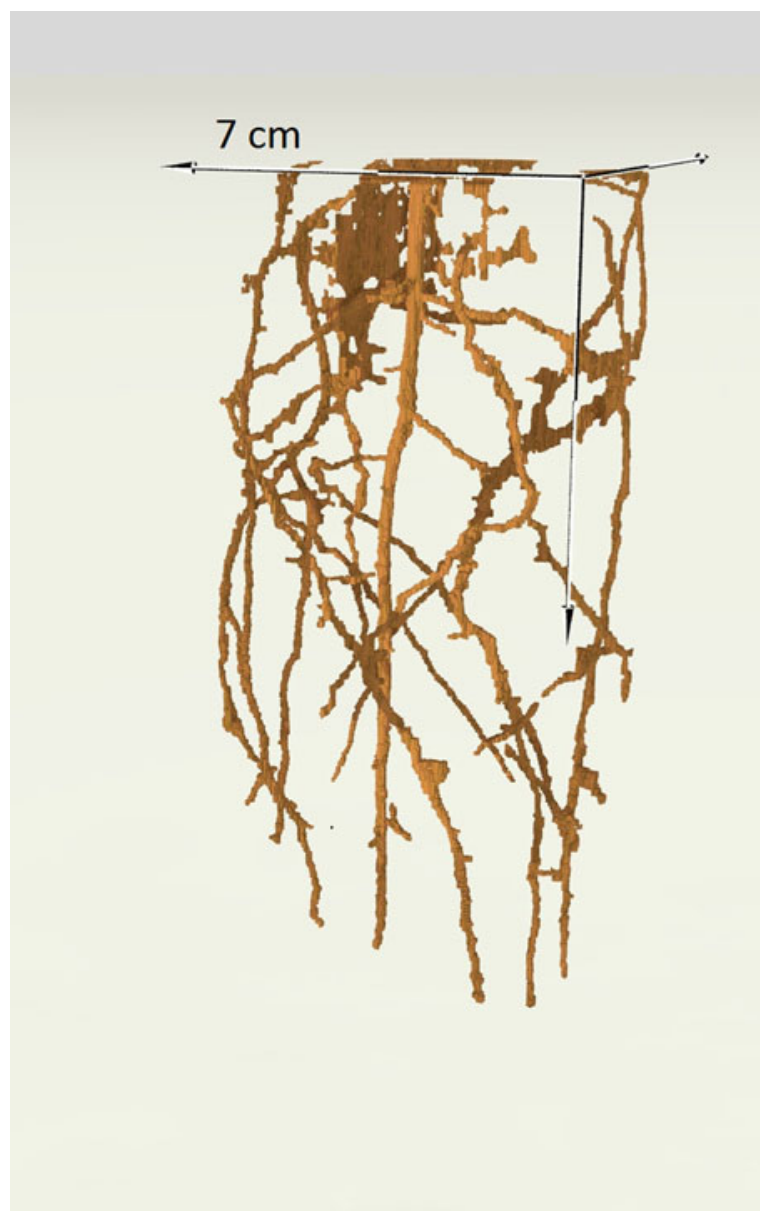

Fig. 2 Three-dimensional visualization of the roots of Lupin II on day 9. The picture was obtained after segmentation of the tomogram taken with the large field of view $(16.4 \mathrm{~cm} \times 16.4 \mathrm{~cm})$. Segmentation and image processing were performed with the software QtQuantIm. The arrows are $7 \mathrm{~cm}$ long soil particles appear white, the mixture of solid, air and water that cannot be spatially resolved appears as light gray, the root appears dark gray, and air-filled pores and gaps appear black. Small gaps at the root-soil interface started forming on day 10 and became larger on day 11. The sample was recorded again on day 14 , 3 days after irrigation. At this stage the gaps were closed. The corresponding horizontal cross-sections at $5 \mathrm{~cm}$ depth are shown in Fig. 4. The horizontal cross-sections show that gaps formed around the tap root between day 10 and 11. Interestingly, no clear gap was visible around lateral roots.

The vertical profiles of the radii of the tap root and of the channel hosting the tap root on day $9,10,11$, and 14 are plotted in Fig. 5. The distance between the two radii gives the size of the gap. Significant gaps around the tap root occurred on day 11 but they were closed on day 14. The radius of the tap root in the top part (depth of 2-7 cm) decreased from $1.53 \pm 0.17$ at day 20 to $1.16 \pm 0.23 \mathrm{~mm}$ on day 11 . The mean and standard deviation were calculated over the vertical profiles plotted in Fig. 5. The decrease in root radius corresponds to the gap size of $0.36 \pm 0.10 \mathrm{~mm}$. Over this time interval, the root radius in the bottom part (depth of $12-17 \mathrm{~cm}$ ) decreased from $0.96 \pm 0.10$ to $0.74 \pm 0.17$ and the gap was $0.18 \pm 0.10 \mathrm{~mm}$. This shows that gap formation was primarily caused by root shrinkage rather than by soil shrinkage. The data show that relative root shrinkage in the top and bottom parts were very similar, being $24 \%$ in the top part and $23 \%$ in the bottom. These results are consistent with Faiz and Weatherley (1982), who reported reduction of root diameter of $20 \%$ when plats were exposed to high transpiration conditions and soil was at a matric potential of $-200 \mathrm{kPa}$.

The average values of tap root radius and gap for Lupin I-IV are plotted in Fig. 6. Upper and lower figures refer to the regions at the top (depth of 2$7 \mathrm{~cm}$ ) and bottom (depth of 12-17 cm), respectively. In all samples gaps along the tap root initiated just before appearance of wilting symptoms. Gaps started to appear at day 11 for Lupin I and II, day 19 for Lupin III, and day 8 for Lupin IV. The corresponding soil matric potentials ranged between $-20 \mathrm{kPa}$ (Lupin I, relatively narrow gaps) and $-50 \mathrm{kPa}$ (Lupin II and III, large gaps). Gap size ranged between $0.1 \mathrm{~mm}$ and $0.36 \mathrm{~mm}$ at the top and $0.02 \mathrm{~mm}$ and $0.18 \mathrm{~mm}$ at the bottom. When the samples were irrigated after wilting symptoms had appeared, hydraulic contact was re- 
Fig. 3 Vertical crosssections of the local tomography at the top $(2-7 \mathrm{~cm}$ depth) and bottom (12$17 \mathrm{~cm}$ depth) of Lupin II. The images refer to the end of the drying cycle (days 911 ) and 3 days after rewatering (day 14). Large quartz grains appear white, roots appear grey, and air filled volumes appear black, corresponding to the decreasing material densities. The tap root, some laterals branching from the tap root, and the increasing air-filled gap developing around the tap root as soil dried (black band along tap root clearly apparent on day 11) are visible

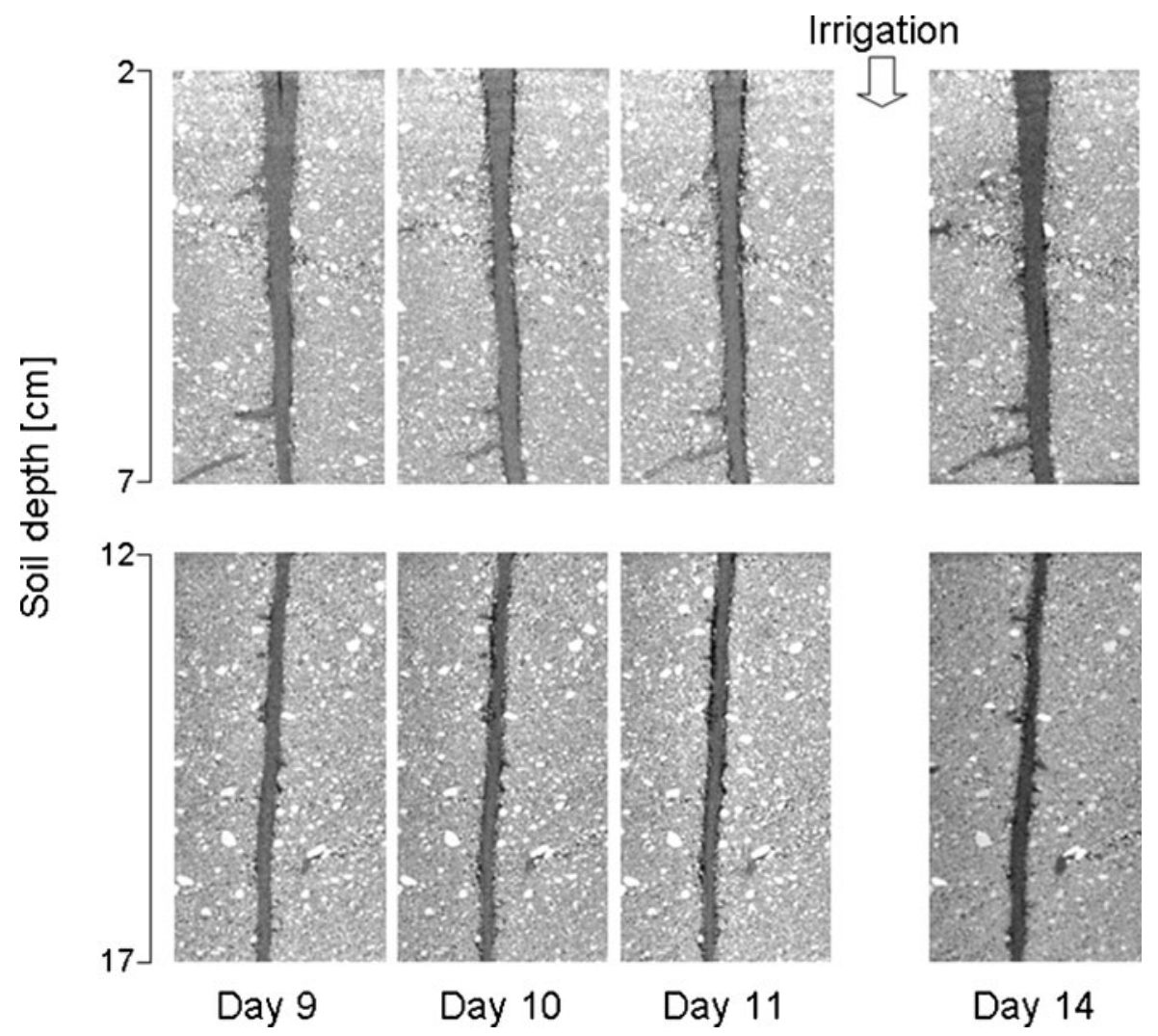

established in the former gap area. Closure of the gaps was caused by root swelling and water refilling.

Root radius and gap size for tap root and laterals and the corresponding soil matric potentials before wilting are given in Table 1. Gaps around lateral roots were smaller than those around tap root. For laterals, the gaps were $0.01-0.05 \mathrm{~mm}$ in the top part and $0.00-0.03$ in the bottom part. The relative shrinkage of the tap root was 9-24\% at the top and 5-23\% at the bottom. The relative shrinkage of the laterals was $0-9 \%$. However, there is a high
Fig. 4 Horizontal crosssections of the local tomography of Lupin II at $5 \mathrm{~cm}$ depth. The images refer to the end of the drying cycle (days 9-11) and 3 days after re-watering (day 14). Large quartz grains appear white, roots appear grey, and air filled volumes appear black, corresponding to the decreasing material densities. The tap root, some laterals branching from the tap root, and the increasing air-filled gap developing around the tap root as soil dried (black circle around tap root clearly apparent on day 11) are visible
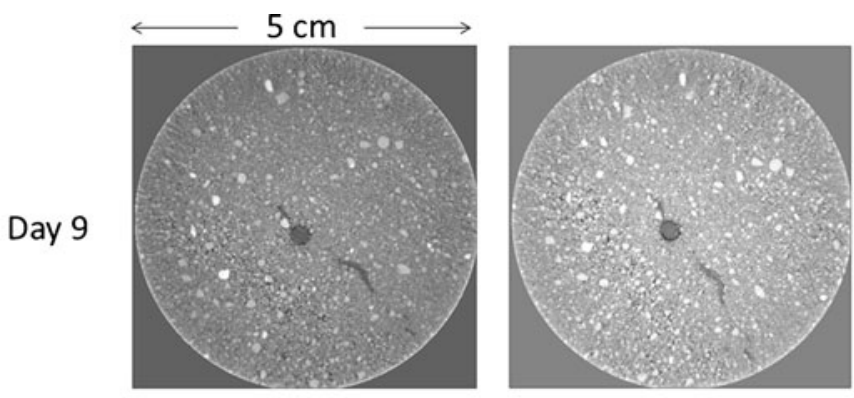

Day 10
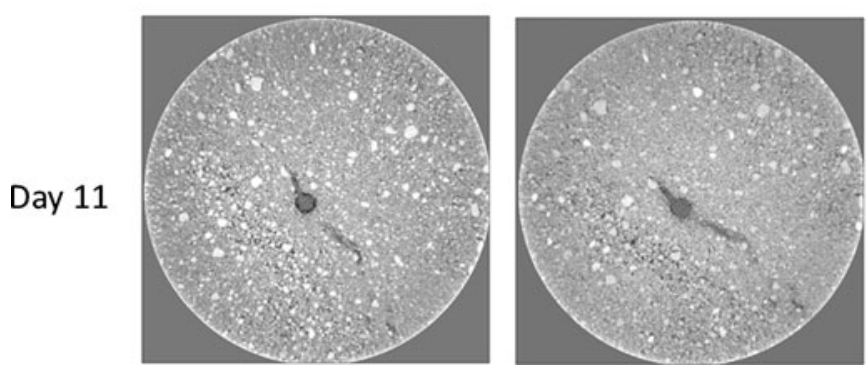

Day 14 

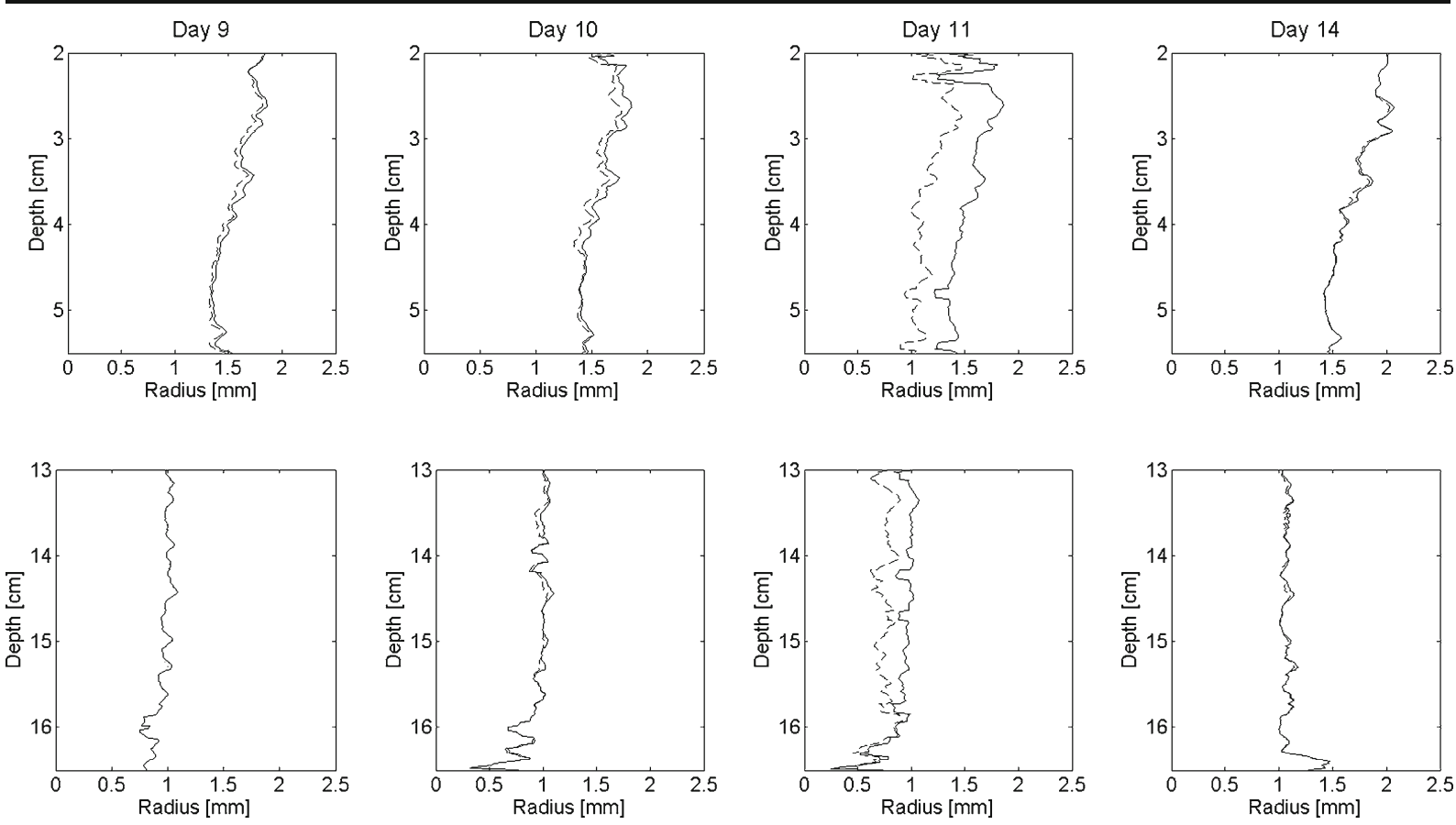

Fig. 5 Radius of tap root (dotted line) and tap root plus gap (solid line) along depth for Lupin II. The radii were calculated for the local tomography

uncertainty in the data for the laterals, because the gaps were smaller than the voxel size $(0.1 \mathrm{~mm})$. Obviously, this raises the question of whether such gaps can be measured using current technology. How could we segment gaps that are smaller than the spatial resolution? The opening of air-filled gaps decreased the grey value of the voxels at the root-soil interface. If the grey value of these voxels was smaller than the threshold fixed for the airfilled space, the voxels were classified as gaps. Our gap

Lupin I

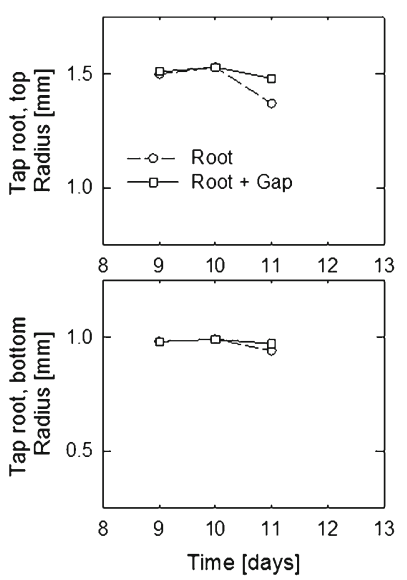

Lupin II
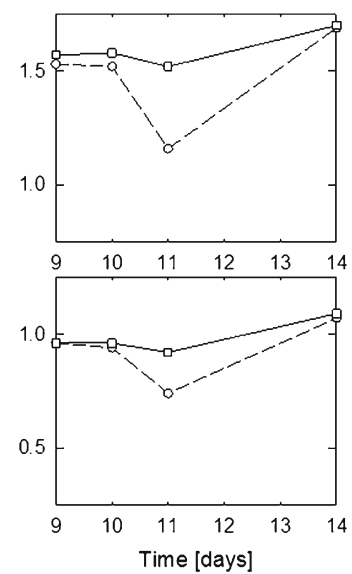

estimation is therefore the result of voxel-averaging and was calculated as the average along all laterals. Better resolution is needed to confirm these data.

The relation between soil matric potential and transpiration is plotted in Fig. 7. The figure shows that Lupin I-IV behaved similarly. Transpiration started to decrease between $-5 \mathrm{kPa}$ and $-10 \mathrm{kPa}$. A partial loss of contact between soil and roots occurred between $-20 \mathrm{kPa}$ and $-40 \mathrm{kPa}$; these points are marked with

Fig. 6 Mean radii of tap root and tap root plus gap, calculated at top (upper figures) and bottom (lower figures) of the four samples 
Table 1 Soil matric potential $\psi$, relative root shrinkage and gap size for tap root (tap) and laterals (lat), at the top and bottom (bot) of the sample, before wilting symptoms were observed.
The relative shrinkage was calculated as the root radius before shrinkage minus the actual root radius divided by the root radius before shrinkage

\begin{tabular}{|c|c|c|c|c|c|c|c|c|c|}
\hline Sample & $\psi[\mathrm{kPa}]$ & $\begin{array}{l}\text { Root shrink } \\
\text { tap, top }\end{array}$ & $\begin{array}{l}\text { Gap tap, } \\
\text { top [mm] }\end{array}$ & $\begin{array}{l}\text { Root shrink } \\
\text { tap, bot }\end{array}$ & $\begin{array}{l}\text { Gap tap, } \\
\text { bot }[\mathrm{mm}]\end{array}$ & $\begin{array}{l}\text { Root shrink } \\
\text { lat, top }\end{array}$ & $\begin{array}{l}\text { Gap lat, } \\
\text { top [mm] }\end{array}$ & $\begin{array}{l}\text { Root shrink } \\
\text { lat, bot }\end{array}$ & $\begin{array}{l}\text { Gap lat, } \\
\text { bot }[\mathrm{mm}]\end{array}$ \\
\hline L I & -20 & $9 \%$ & 0.11 & $5 \%$ & 0.03 & $5 \%$ & 0.02 & $3 \%$ & 0.00 \\
\hline L II & -50 & $24 \%$ & 0.36 & $23 \%$ & 0.18 & $9 \%$ & 0.05 & $9 \%$ & 0.03 \\
\hline L III & -40 & $17 \%$ & 0.23 & $20 \%$ & 0.02 & $4 \%$ & 0.01 & $1 \%$ & 0.02 \\
\hline L IV & -40 & $19 \%$ & 0.10 & $13 \%$ & 0.03 & $1 \%$ & 0.02 & $8 \%$ & 0.00 \\
\hline
\end{tabular}

dotted-line stars and they refer to gaps of approximately $0.1 \mathrm{~mm}$. Continuous gaps larger than $0.1 \mathrm{~mm}$ established below $-40 \mathrm{kPa}$ (solid line stars).

\section{Discussion}

Our results demonstrate that gaps appeared after transpiration rate started to decrease. The decrease in transpiration was explained by the low hydraulic conductivity of soil at matric potentials lower than $-5 \mathrm{kPa}$, as also reported by Carbon (1973). The reduced soil hydraulic conductivity limited the water flow into roots and caused the initial shrinkage of roots and the gap formation. Gaps limited even more the water flow into root, roots shrank further, and, as in a chain reaction, the water flow into roots became more and more limited until the plants finally wilted. Gap formation seems therefore a consequence and not the cause of limiting water flow from soil to roots as suggested by Faiz and Weatherley (1982): "Root contraction could hardly initiate a rise in the interfacial resistance since an initial increase in resistance is necessary to bring about a fall in water content of the root tissue and hence a reduction in root diameter". However, it might be that gaps smaller than the spatial resolution were already present before transpiration decreased. Transpiration rate started to decrease at a soil matric potential between $-5 \mathrm{kPa}$ and $-10 \mathrm{kPa}$. At such a matric potential, gaps larger than $0.03 \mathrm{~mm}$ (gap diameter) would be drained and could limit water flow. Although a higher resolution is required to exclude this hypothesis, there are two arguments suggesting that air-filled gaps larger than 0.03 were not present: 1) if such gaps were present, the gray values in the voxels at the root-soil interface would have been decreased and some of these voxels would have been classified as gaps; 2) independent experiments with
Fig. 7 Relative transpiration versus soil matric potential during the drying period for Lupin I -IV. The time when roots started to lose contact with the soil is marked with dotted-line open stars. The time when a clear and continuous gap formed along the roots is marked with a solid-line open star

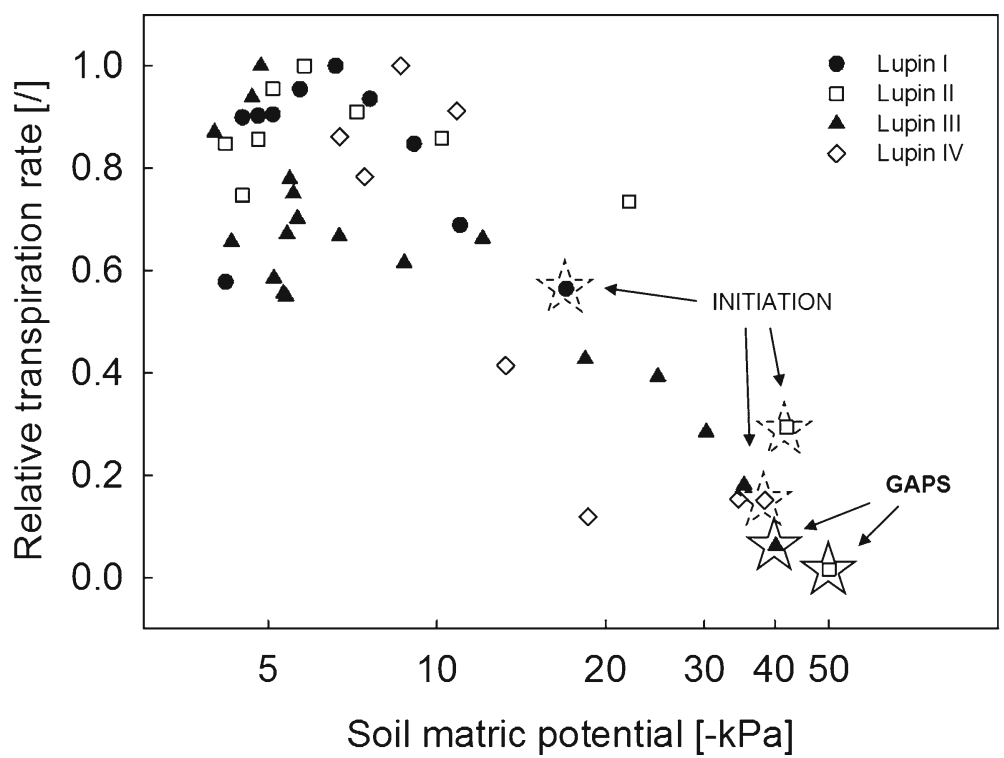




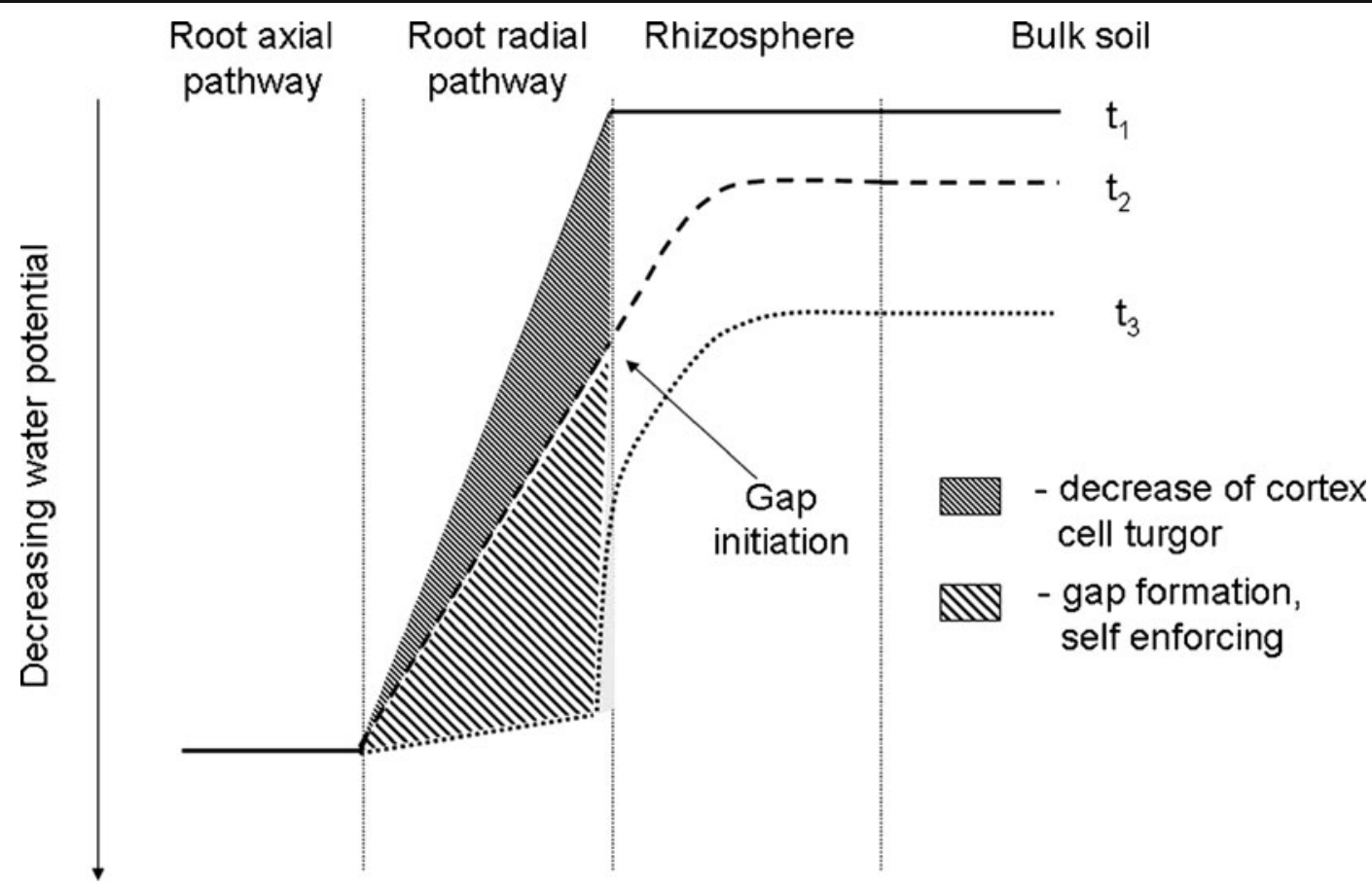

Fig. 8 Conceptual model of root shrinkage, assuming constant water potential in the xylem and no osmotic adjustment of root cortex cells. At time step $1\left(\mathrm{t}_{1}\right)$ the soil is wet and the largest gradients in water potential occur in root radial pathway. As soil

neutron radiography (Carminati et al. 2010; Moradi et al. 2011) showed that during a drying period the water content in the rhizosphere of lupins was higher than in the bulk soil. This result was more pronounced for lateral roots and was explained by mucilage exuded by roots. The observed high water content in the rhizosphere and the hypothesized role of the mucilage suggest that roots were in "good" hydraulic contact with the soil before transpiration rate started to decrease. Similarly, root hairs may close the gap between soil and root, either by directly taking up water or by creating a capillary bridge for water to flow across the gap. White and Kirkegaard (2010) found a correlation between gap size and density of root hairs, suggesting a potential role of root hairs in the adaptation of plants to the presence of gaps and macropores. However, we cannot exclude that some partial contact and narrow gaps occurred earlier at some locations. All that we can conclude is that the large and continuous gaps between the tap root and soil appeared after the decrease in transpiration and were not the cause of the decreased transpiration.

The tomograms show a vertical gradient in gap formation around the tap root, with larger gaps at the dries $\left(t_{2}\right)$, steep gradients in water potential occur around the root (rhizosphere). At this stage, roots will start to lose turgor and an air gap will open up $\left(t_{3}\right)$. The sketch of the water potential profile is not to scale

basal part and smaller gaps towards the apical part. Gaps initiated near the root collar, that lost contact to the soil before the apical part of the tap root - compare gap size at top and bottom of Lupin I and IV. As soil matric potential decreased (Lupin II and IV), the gap size along the tap root was proportional to the root radius. The gap was equal to the root shrinkage and relative root shrinkage was quite uniform along depth. The uniform shrinkage of the tap root could be explained by a quite uniform xylem potential, a probable consequence of high xylem conductivity, and by a uniform ratio of stele and cortex cross sectional area, with the latter being more susceptible to shrinkage.

Much smaller gaps were observed around lateral roots, which shrank by a maximum of $9 \%$. This result is at the limit of, and probably below, our spatial resolution, and needs to be verified with higher spatial resolution. However, the possibility that laterals remain in a closer contact with the soil compared to the tap root has important implications for soil-plant water relations and deserves discussion. Why did lateral roots shrink less than the tap root? 
One possibility is the different elasticity of laterals and tap root. Laterals may have a smaller cortex in proportion to the total cross section. Since cortex shrinks more than the stele in lupin, this would result in a smaller relative shrinkage of lateral roots.

A second possibility is that the xylem water potential in lateral roots was higher than in the tap root. This could be caused by a limited xylem conductivity of the laterals. If the xylem vessels of the laterals were not yet mature, their axial hydraulic resistance could be significant. The axial resistance of laterals could be further increased by unfavorable connections between laterals and tap root, as reported by Byrne et al. (1977) in soybean.

An additional possibility is related to water flow across the root-soil interface. Figure 8 illustrates a conceptual model of root shrinkage based on the ratio between root and soil conductivity. When soil is wet $\left(t_{1}\right.$, Fig. 7) and its conductivity is high, the largest gradients in water potential occur across the root radial pathway. As soil water content decreases $\left(t_{2}\right)$, steep gradients in water potential arise between bulk soil and root surface because of the non-linear decrease of soil conductivity and the radial geometry of the water flow. The average water potential across the radial pathway becomes more negative. If cortex cells have no osmotic adjustment, their turgor pressure will start to decrease and shrinkage of cortex cells begins $\left(\mathrm{t}_{3}\right)$. For a relative shrinkage of $1 \%$, a tap root with radius of $1,370 \mu \mathrm{m}$ will form a gap of $14 \mu \mathrm{m}$, while a lateral with radius of $190 \mu \mathrm{m}$ will form a gap of $2 \mu \mathrm{m}$. The air entry values for such gaps are approximately $-20 \mathrm{kPa}$ and $-150 \mathrm{kPa}$, respectively. Hence the initial gap around tap root will be air filled at higher matric potentials and the hydraulic connection between soil and root will be lost earlier. Due to the reducing conductivity as gaps become large, the process will be self enhancing - i.e. once a gap is initiated, water uptake can occur only through vapour phase, the water potential in the radial pathway will become more negative and cortex cells will undergo further shrinkage. Given the same relative shrinkage, the initial gap will be larger around tap roots than laterals and it will be drained at a less negative water potential. Thus, the self-enhancing process will start earlier for tap roots and tap roots will shrink more, also in relative terms.

A final hypothesis why laterals may shrink less than the tap root, is the higher concentration of mucilage around laterals and more distal parts of roots. In recent papers, Carminati et al. (2010) and Moradi et al. (2011) observed increasing water contents towards roots. This result, contradicting the common paradigm of decreasing water content towards roots, was explained by the high water holding capacity of mucilage. This effect was more pronounced around laterals and in the distal parts of roots. As shown in a modelling exercise by Carminati et al. (2011), mucilage attenuates the gradients in water potential in the rhizosphere and consequently will reduce the loss of turgidity of root cells. Higher concentration of mucilage around laterals could therefore explain the different shrinkage of tap root and laterals and could help lateral roots to remain in contact with the soil.

To date, researchers have regarded gaps between soil and roots as a negative process for plant-soil water relations. However, air-filled gaps will partly isolate the roots from soil. For plants exposed to dry soils this may imply lower water loss from roots to soil, which in this case will occur by vapour diffusion, as suggested by North and Nobel (1997). Gap formation around the tap root, in particular in the top soil, and persistence of the contacts at the laterals may be a good strategy to enable plants to isolate parts of the roots that are in the dry soils, while younger roots continue to grow in wetter regions. Similarly, gaps and isolation of the most proximal root parts may not necessarily induce a reduction in root water uptake, as this can be compensated by more apical parts, as suggested by Garrigues et al. (2006) and Zwieniecki et al. (2003).

Acknowledgements We acknowledge Rebecca Terrey for technical assistance.

Open Access This article is distributed under the terms of the Creative Commons Attribution License which permits any use, distribution, and reproduction in any medium, provided the original author(s) and the source are credited.

\section{References}

Aravena JE, Berli M, Ghezzehei TA, Tyler SW (2011) Effects of root-induced compaction on rhizosphere hydraulic properties - x-ray microtomography imaging and numerical simulations. Environ Sci Technol 45:425-431

Byrne JM, Pesacreta TC, Fox JA (1977) Development and structure of the vascular connection between the primary and secondary roots of Glycine max (L.) Merr. Am J Bot 64:946-959 
Carbon BA (1973) Diurnal water stress in plants grown on a coarse soil. Aust J Soil Res 24:33-42

Carminati A, Vetterlein D, Weller U, Vogel H-J, Oswald SE (2009) When roots lose contact. Vadose Zone J 8:805-809

Carminati A, Moradi A, Vetterlein D, Vontobel P, Lehmann E, Weller U, Vogel H-J, Oswald SE (2010) Dynamics of soil water content in the rhizosphere. Plant Soil 332:163-176

Carminati A, Schneider CL, Moradi AB, Vetterlein D, Vogel HJ, Hildebrandt A, Weller U, Schüler L, Oswald SE (2011) Rhizosphere increases water availability to roots: a microscopic modelling study. Vadose Zone J 10:1-11

Czarnes S, Hallett PD, Bengough AG, Young IM (2000) Rootand microbial-derived mucilages affect soil structure and water transport. Eur J Soil Sci 51:435-443

Draye X, Kim Y, Lobet G, Javaux M (2010) Model-assisted integration of physiological and environmental constraints affecting the dynamic and spatial patterns of root water uptake from soils. J Exp Bot 61:2145-2155

Faiz S, Weatherley P (1982) Root contraction in transpiring plants. New Phytol 92:333-343

Garrigues E, Doussan C, Pierret A (2006) Water uptake by plant roots: I-formation and propagation of a water extraction front in mature root systems as evidenced by $2 \mathrm{D}$ light transmission imaging. Plant Soil 283:83-98

Glass RJ, Steenhuis TS, Parlange J-Y (1989) Wetting front instability: 2. Experimental determination of relationships between system parameters and two-dimensional unstable flow field behavior in initially dry porous media. Water Resour Res 25:1195-1207

Gregory PJ (2006) Roots, rhizosphere and soil: the route to a better understanding of soil science? Eur J Soil Sci 57:2-12

Hallet PD, Gordon DC, Bengough AG (2003) Plant influence on rhizosphere hydraulic properties: direct measurements using a miniaturized infiltrometer. New Phytol 157:597-603

Hinsinger P, Bengough AG, Vetterlein D, Young I (2009) Rhizosphere: biophysics, biogeochemistry and ecological relevance. Plant Soil 321:117-152

Huck MG, Klepper B, Taylor HM (1970) Diurnal variation in root diameter. Plant Physiol 45:529-530

Moradi AB, Carminati A, Vetterlein D, Vontobel P, Lehmann E, Ulrich W, Hopmans YW, Vogel H-J, Oswald SE (2011)
Three-dimensional visualization and quantification of water content in rhizosphere. New Phytol 192:653-663

Nobel PS, Cui M (1992) Hydraulic conductances of the soil, the root-soil air gap, and the root: changes for desert succulents in drying soil. J Exp Bot 43:319-326

North GB, Nobel PS (1997) Root-soil contact for the desert succulent Agave deserti in wet and drying soil. New Phytol $135: 21-29$

Passioura JB (1980) The transport of water from soil to shoot in wheat seedlings. J Exp Bot 31:333-345

Read DB, Bengough AG, Gregory PJ, Crawford JW, Robinson D, Scrimgeour CM, Young IM, Zhang K, Zhang X (2003) Plant roots release phospholipid surfactants that modify the physical and chemical properties of soil. New Phytol 157:315-326

Rudin LI, Osher S, Fatemi E (1992) Nonlinear total variation based noise removal algorithms. Physica D 60: 259-268

Veen BW, Van Noordwijk M, De Willigen P, Boone FR, Kooistra MJ (1992) Root-soil contact of maize, as measured by a thinsection technique. III. Effects on shoot growth, nitrate and water uptake efficiency. Plant Soil 139:131-138

Vetterlein D, Marschner H, Horn R (1993) Microtensiometer technique for in situ measurements of soil matric potential and root water extraction from a sandy soil. Plant Soil 149:263-273

Vogel H-J, Weller U, Schlüter S (2010) Quantification of soil structure based on Minkowski functions. Comput Geosci 36:1236-1245

Whalley WR, Riseley B, Leeds-Harrison PB, Bird NRA, Leech PK (2005) Structural differences between bulk and rhizosphere soil. Eur J Soil Sci 56:353-360

White RG, Kirkegaard JA (2010) The distribution and abundance of wheat roots in a dense structured subsoil implications for water uptake. Plant Cell Environ 33: 133-148

Young IM (1995) Variation in moisture contents between bulk soil and the rhizosheath of wheat (Triticum aestivum L. cv. Wembley). New Phytol 130:135-139

Zwieniecki M, Thompson M, Holbrook N (2003) Understanding the hydraulics of porous pipes: tradeoffs between water uptake and root length utilization. J Plant Growth Regul 21:315-323 